\title{
Numerical Modelization of the Flow in Centrifugal Pump: Volute Influence in Velocity and Pressure Fields
}

\author{
Miguel Asuaje \\ LEMFI, Site ENSAM FRE CNRS 2866, ENSAM, 151 Boulevard de l'Hôpital, 75013 Paris, France \\ Email:miguel.asuaje@paris.ensam.fr \\ Farid Bakir \\ LEMFI, Site ENSAM FRE CNRS 2866, ENSAM, 151 Boulevard de l'Hôpital, 75013 Paris, France \\ Email: farid.bakir@paris.ensam.fr

\section{Smaïne Kouidri} \\ LEMFI, Site ENSAM FRE CNRS 2866, ENSAM, 151 Boulevard de l'Hôpital, 75013 Paris, France \\ Email: smaine.kouidri@paris.ensam.fr

\section{Frank Kenyery} \\ Universidad Simón Bolívar, Laboratorio de Conversión de Energía Mecánica, Apartado Postal 89000, Caracas, Venezuela \\ Email:fekenyery@usb.ve \\ Robert Rey \\ LEMFI, Site ENSAM FRE CNRS 2866, ENSAM, 151 Boulevard de l'Hôpital, 75013 Paris, France \\ Email: robert.rey@paris.ensam.fr \\ Received 5 January 2004
}

\begin{abstract}
A 3D-CFD simulation of the impeller and volute of a centrifugal pump has been performed using CFX codes. The pump has a specific speed of 32 (metric units) and an outside impeller diameter of $400 \mathrm{~mm}$. First, a 3D flow simulation for the impeller with a structured grid is presented. A sensitivity analysis regarding grid quality and turbulence models were also performed. The final impeller model obtained was used for a 3D quasi-unsteady flow simulation of the impeller-volute stage. A procedure for designing the volute, the nonstructured grid generation in the volute, and the interface flow passage between the impeller and volute are discussed. This flow simulation was carried out for several impeller blades and volute tongue relative positions. As a result, velocity and pressure field were calculated for different flow rates, allowing to obtain the radial thrust on the pump shaft.
\end{abstract}

Keywords and phrases: CFD, centrifugal pump, unsteady flow, radial thrust.

\section{INTRODUCTION}

The design of radial- and mixed-flow centrifugal pumps remains still very empirical because it relies on the use of a number of experimental and statistical rules. However, except for the principal dimensions, this fact is rather logical since the selection of a large number of second-order parameters must be done in order to define the complete impeller

This is an open access article distributed under the Creative Commons Attribution License, which permits unrestricted use, distribution, and reproduction in any medium, provided the original work is properly cited. and volute geometry. This choice is often guided by several optimization criteria such as uniform flow, low machine footprint, stable characteristic curves, and performance improvement (efficiency, NPSH, noise, pressure fluctuations, etc.). During the last few years, the design and performance analysis of turbomachinery have experienced great progress due to the joint evolution of computer power and the accuracy of numerical methods.

Recently, several authors (Paßrucker and Van den Braembussche [1]; Cravero [2]; Sloteman et al. [3]; Goto et al. [4]) have proposed integral procedures to design and analyze turbomachines combining different computational 
tools. Mostly, these procedures combine a one-dimensional (1D) performance analysis method with a quasi-threedimensional (Q-3D) method to verify the optimum pump geometry. The optimum geometry has been validated using 3D CFD flow simulations, concluding the effectiveness and the importance of the $1 \mathrm{D}$ and $\mathrm{Q}-3 \mathrm{D}$ approaches on pump design.

\subsection{CFD in the turbomachinery}

The CFD occupies today a very significant place in the disciplines of fluid mechanics and turbomachinery due to the great progress in the development of numerical methods and computing power. However, the initially use of CFD tools to design a new machine represents a nonrealistic procedure (see Arnone et al. [5]). The design of a new machine (or upgrading an existing machine) would require a great investment of time without guarantee of success. Along with the introduction of CFD tools, the incorporation of computeraided design (CAD) codes has speeded up the design process because of a faster geometry and grid generation (see Asuaje et al. [6]). Nevertheless, the problem always reduces down to the selection of reasonable values for a number of geometric parameters. At this point, the "know-how," skills and talent of the designer remain the principal ingredients for designing and optimizing a machine (see Yedidiah [7]).

$1 \mathrm{D}$ and Q-3D approaches to design and analyze turbomachines can be considered well adapted and powerful enough for most applications. However, for designing a highperformance pump, it is necessary to accurately determine the internal flow in the pump. Results from the literature regarding CFD show a good correspondence with experimental results. Blanco-Marigorta et al. [8] have studied the influence of the volute geometry and relative position between impeller and volute casing. They performed a $2 \mathrm{D}$ unsteady flow simulation in centrifugal pump ( $n s=30)$ using the commercial code FLUENT.

González et al. [9] continued the preceding study towards the 3D simulation. A very satisfactory comparison between calculations and experimental results is presented (see Parrondo-Gayo et al. [10])

Several others' works (Gu et al. [11]; Muggli et al. [12]; Cravero and Marini [13]) have shown good agreement between simulation and experimental results.

If 3D techniques keep growing in power and help to understand the 3D flow behavior in the machine, the design cycle of turbomachinery will be closed with the construction and testing of a prototype. The purpose of the present paper is to show a 3D numerical study of a centrifugal pump. Simulations have been done with the commercial CFD software CFX-TASCflow 2.12 and CFX 5.5.

\section{IMPELLER 3D FLOW SIMULATION}

A 3D CFD flow simulation was carried out on an isolated impeller of a mixed-flow centrifugal pump with specific speed of 32 (impeller NS32). The main pump parameters and geometry are presented in Figure 1 and Table 1.

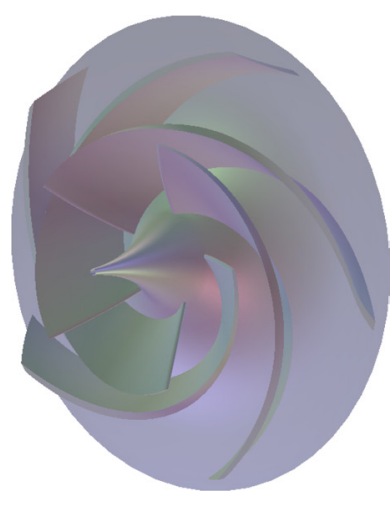

FIgURE 1: Visualization 3D of NS32 impeller.

TABLE 1: Geometrical parameters of the pump $N_{S}=32$.

\begin{tabular}{|c|c|c|}
\hline \multicolumn{3}{|c|}{ Pump NS32. MP 250-200-400 } \\
\hline Parameter & Value & Description \\
\hline \multicolumn{3}{|c|}{ Impeller } \\
\hline$R_{0}$ & $115 \mathrm{~mm}$ & Inlet flange radius \\
\hline$R_{1}$ & $75 \mathrm{~mm}$ & Mean impeller inlet radius \\
\hline$b_{1}$ & $85.9 \mathrm{~mm}$ & Inlet impeller width \\
\hline$\beta_{1}$ & $70^{\circ}$ & Inlet blade angle \\
\hline$\theta_{1}$ & $37^{\circ}$ & Blade LE inclination angle \\
\hline$R_{2}$ & $204.2 \mathrm{~mm}$ & Mean impeller outlet radius \\
\hline$b_{2}$ & $42 \mathrm{~mm}$ & Outlet impeller width \\
\hline$\beta_{2}$ & $63^{\circ}$ & Outlet blade angle \\
\hline$\theta_{2}$ & $90^{\circ}$ & Blade TE inclination angle \\
\hline $\mathrm{Na}$ & 5 & Blade number \\
\hline$e$ & $8 \mathrm{~mm}$ & Blade thickness \\
\hline \multicolumn{3}{|c|}{ Volute } \\
\hline$R_{3}$ & $218 \mathrm{~mm}$ & Base volute radius \\
\hline$b_{3}$ & $50 \mathrm{~mm}$ & Volute width \\
\hline$\phi_{\text {outlet }}$ & $200 \mathrm{~mm}$ & Outlet flange diameter \\
\hline
\end{tabular}

The first task to accomplish on a numerical flow simulation is the definition of the geometry, followed by the grid generation. This step is maybe the most important step in this work. For the study of an isolated impeller, assuming an axisymmetric flow simplifies the domain to a single blade passage. The simulation domain for the impeller pump NS32 is schematized in Figure 2. A structured grid was created using the CFX-Turbogrid software.

\subsection{Simulation parameters and boundary conditions}

The general parameters and boundary conditions used for the $3 \mathrm{D}$ flow simulation of the impeller are summarized in Table 2.

For all simulations, the boundary conditions are as follows.

(i) Inlet: total pressure applied in the rotation axis direction.

(ii) Outlet: imposed mass flow. 


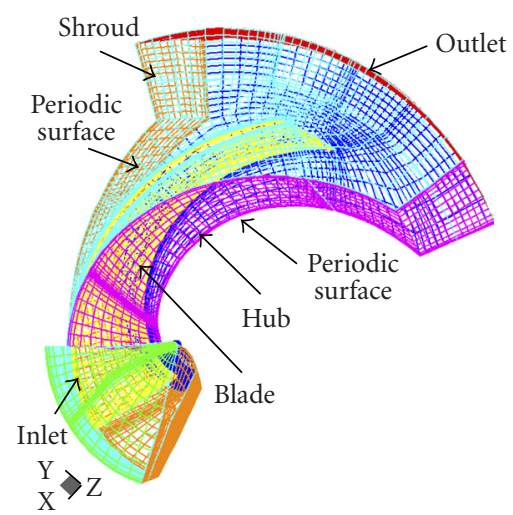

(a)

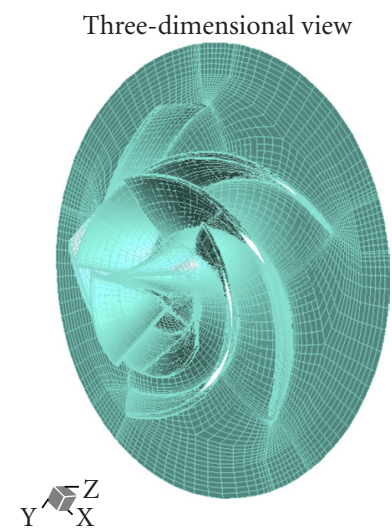

(b)

FIGURE 2: Impeller NS32: flow simulation domain and structured grid.

TABLE 2: Impeller NS32: simulation parameters.

\begin{tabular}{lc}
\hline Parameters & CFX-TASCflow \\
\hline Flow simulation domain & $\begin{array}{c}\text { Single impeller flow channel } \\
\text { (periodic interface }) \\
\text { Grid }\end{array}$ \\
Fluid & $\begin{array}{c}\text { Structured } \\
\text { Inlet }\end{array}$ \\
Outlet & Total pressure $=101325(\mathrm{~Pa})$ \\
Turbulence model & Mass flow $=$ variable $(\mathrm{kg} / \mathrm{s})$ \\
Discretization & $K-\varepsilon / K-\omega / S S T$ \\
Maximum residual convergence & Second order \\
Criteria & $10^{-4}(\mathrm{RSM})$ \\
\hline
\end{tabular}

(iii) Periodic: two symmetry surfaces positioned in the middle of the blade passage.

(iv) Wall: general boundary condition by default.

The simulation domain at the inlet and outlet sections was sufficiently extended to allow inlet recirculation and the elliptic influence of the flow.

\subsection{Mesh independence}

Theoretically, the errors in the solution related to the grid must disappear for an increasingly fine mesh (see Ferziger and Péric [14]). The pump head at nominal flow conditions was taken as the parameter to evaluate seven grids (Table 3 ) and determine the influence of the mesh size on the solution. The selected convergence criteria were a maximum residual of $10^{-4}$. In Figure 3, it is observed how the calculated impeller head reaches an asymptotic value as the number of nodes increases. According to this figure, the grid E (49824 nodes) is considered to be sufficiently reliable to ensure mesh independence.

Looking further into the mesh size influence, Figures 4 and 5 present the meridional velocity profile at the leading
TABLE 3: Evaluated grid sizes.

\begin{tabular}{lc}
\hline Characteristics & Number of nodes \\
\hline Grid $A$ & 10879 \\
Grid $B$ & 19097 \\
Grid $C$ & 28905 \\
Grid $D$ & 41174 \\
Grid $E$ & 49824 \\
Grid $F$ & 79065 \\
Grid $G$ & 101637 \\
\hline
\end{tabular}

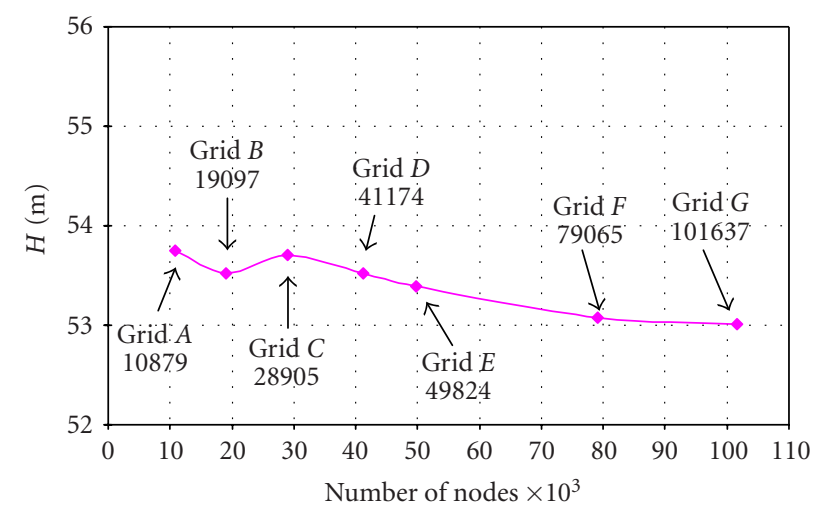

FIGURE 3: Influence of grid size on impeller head.

and trailing edges of the blade, as a function of the number of nodes. The evolution of the velocity profile at the trailing edge confirms the previous result. A good convergence can be only achieved with a grid size which is equal to or higher than the grid $E$.

\subsection{Turbulence models}

Three criteria influence the choice of a turbulence model: (1) the physical nature of the problem, (2) the quality of attended 


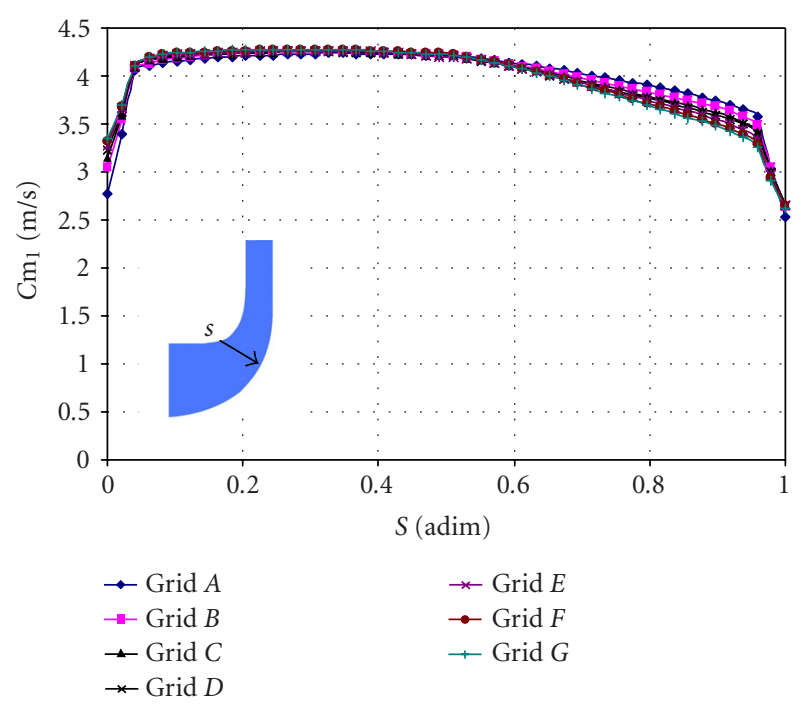

FIgURE 4: Influence of grid size on the meridional velocity at the leading edge of the blade: CFX-TASCflow code and impeller NS32.

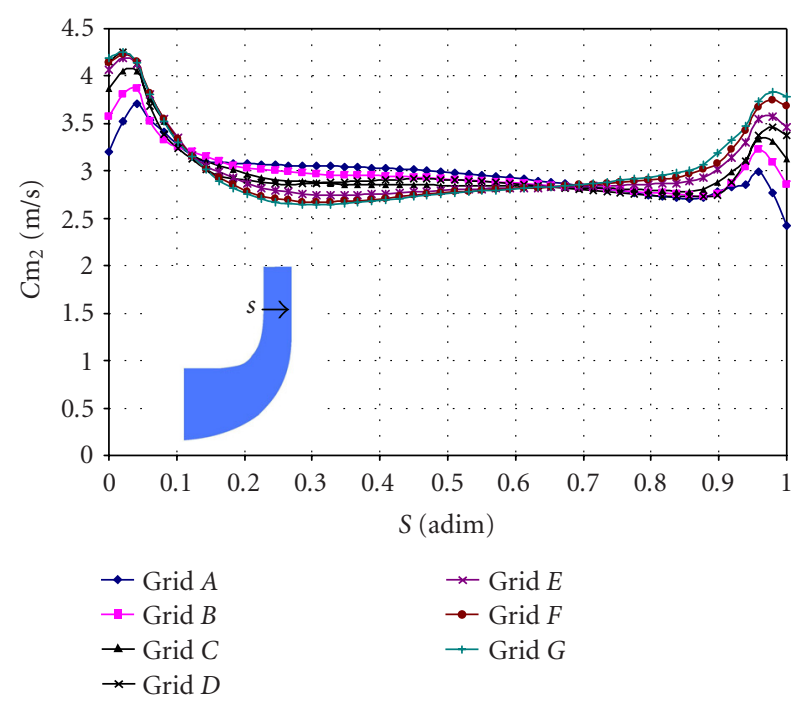

FIGURE 5: Influence of grid size on the meridional velocity at the trailing edge of the blade: CFX-TASCflow code and impeller NS32.

results, and (3) computing power (see Bradshaw [15]). Depending on the flow complexity, this choice is always crucial when using CFD codes. Nevertheless, the traditional RANS models, like $\kappa-\varepsilon$ or $\kappa-\omega$, are widely used and yield satisfactory results.

According to the flow complexity, this choice is always a delicate point for the use of CFD codes. Nevertheless, the traditional RANS models, like $\kappa-\varepsilon$ or $\kappa-\omega$, are amply used and produce satisfactory results.

The models $\kappa-\varepsilon, \kappa-\omega$, and SST were evaluated in the impeller flow simulation, under similar conditions and for the nominal flow rate of the pump. This part of the study

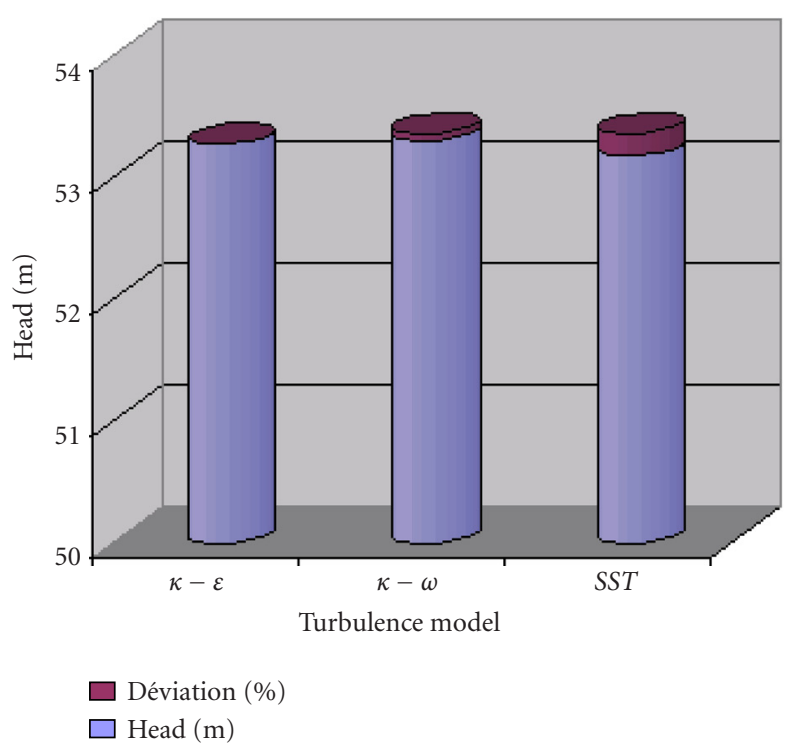

FIGURE 6: Influence of turbulence model on the calculated pump head.

was carried out on mixed-flow impeller by using the grid $E$, with a maximum residue lower than or equal to $10^{-4}$.

Figure 6 shows the influence of the three turbulence models on the calculated pump head. The calculated head $H$ varies very slightly (less than $0.02 \%$ ).

The same tendency is observed in Figures 7 and 8, where no significant influence of the turbulence model on the meridional velocity field and velocity profile near the wall is observed.

\section{IMPELLER-VOLUTE 3D QUASI-UNSTEADY FLOW SIMULATION}

The $3 \mathrm{D}$ views of the impeller, volute casing, and impellervolute assembly are shown in Figure 9.

The volute-casing skeleton was imported by the preprocessor of CFX-5 (CFX-Build) to build the surfaces and volumes of the volute. After this process was conducted, the grid generation was completed. Figure 10 shows the three steps to generate the grid of the volute casing.

The original configuration of the outlet volute casing was modified in order to avoid the occurrence of a big recirculation in that area. The extension of the volute outlet is essential for numerical and physical reasons, since convergence problems and related flow instabilities are prevented if the swirling zone is captured into the simulation domain.

As it will be shown later, another swirling zone appears in the impeller inlet for flow rates lower than the rates corresponding to the best efficiency point. For this reason, it was also necessary to extend the impeller inlet upstream (see Figure 11).

Due to the change between the reference frame of the rotating impeller and static volute casing, the interaction of impeller volute has been simulated using the Frozen-Rotor 


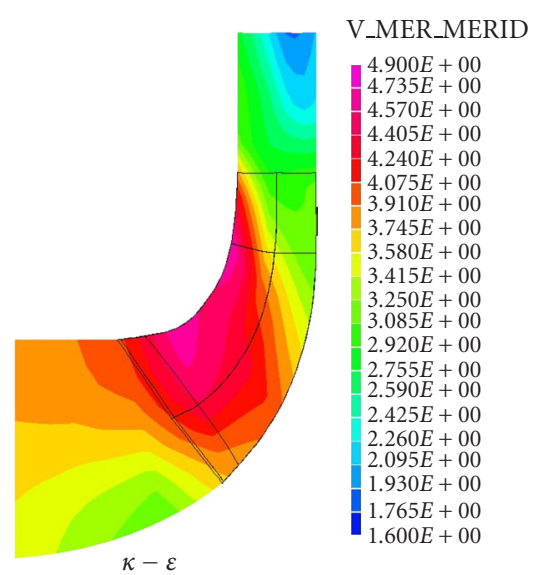

(a)

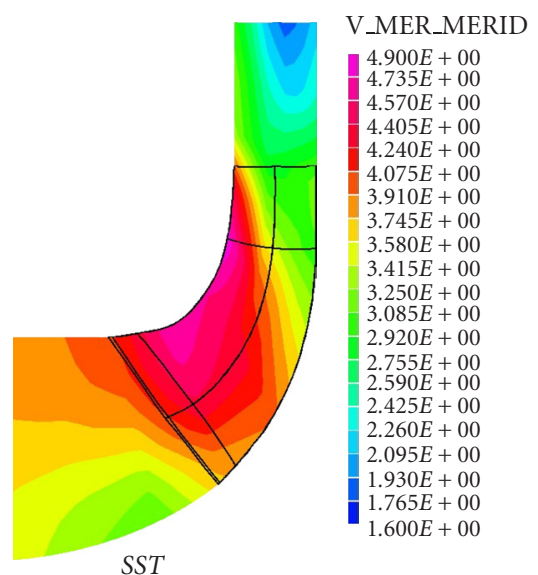

(b)

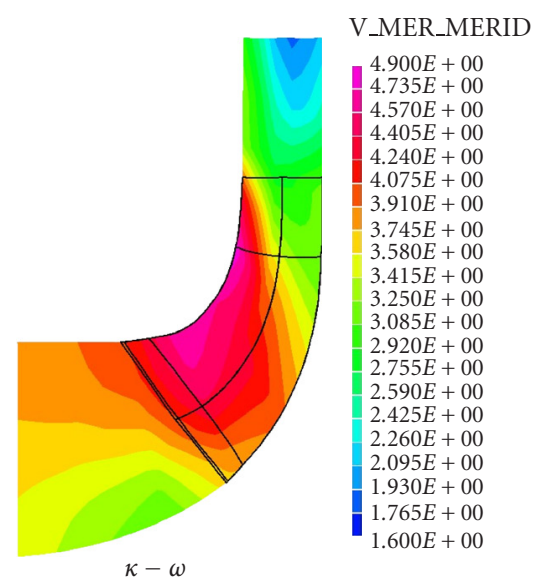

(c)

FIGURE 7: Influence of turbulence model on the meridional velocity field.

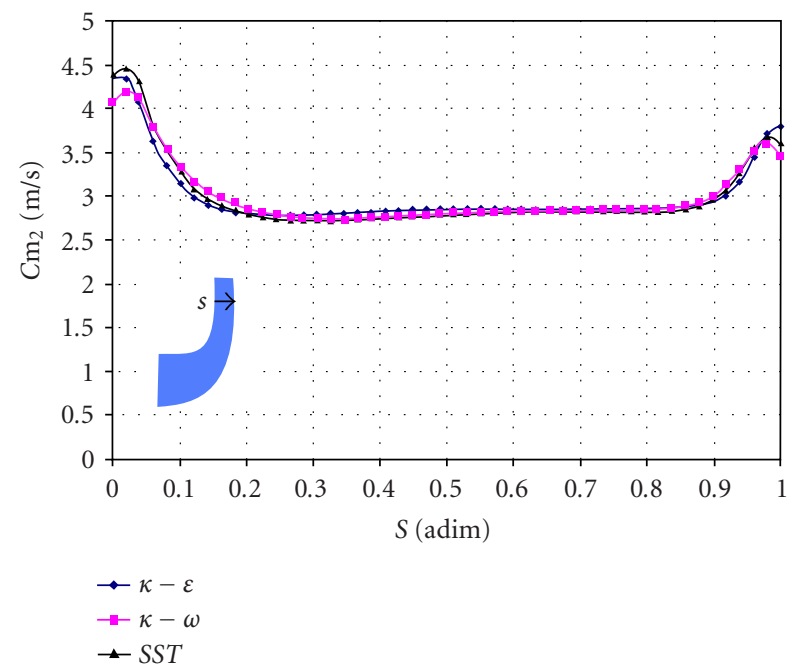

FIGURE 8: Influence of turbulence model on the velocity profile at the trailing of the blade.
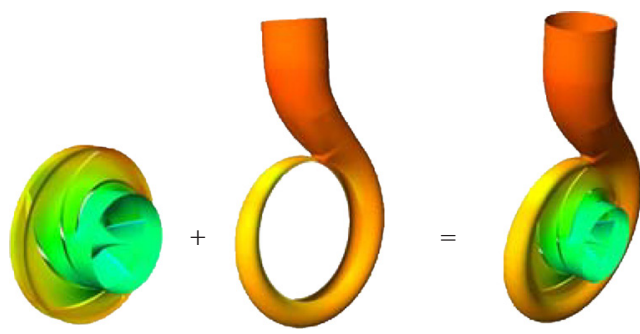

Figure 9: 3D elements of the pump NS32.

interface model. In this model, the simulation is performed for a determined relative position of the machine components, then this relative position is changed step by step in a quasi-unsteady calculation.

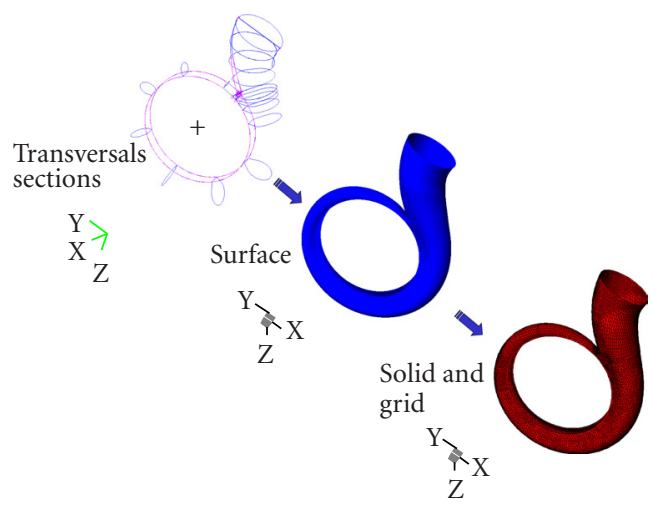

FIGURE 10: Grid generation steps of pump-volute casing NS32.

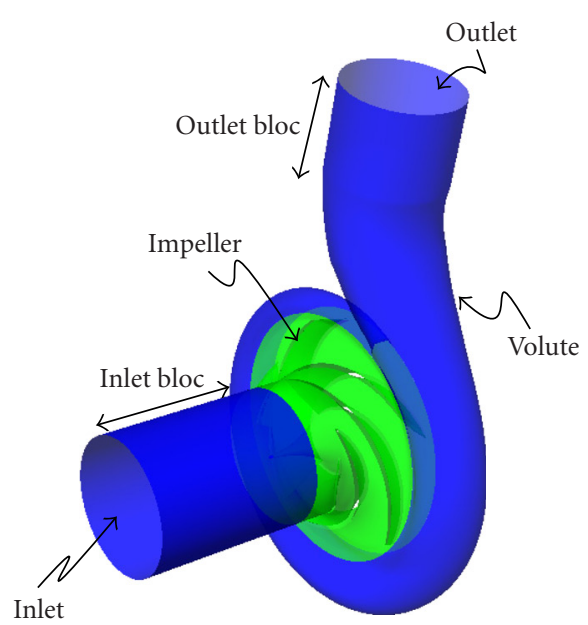

Figure 11: Definition of flow simulation domain showing extend of inlet and outlet sections.

For the pump studied, nine relative positions have been analyzed starting at the position of $\alpha=0^{\circ}$ named position 


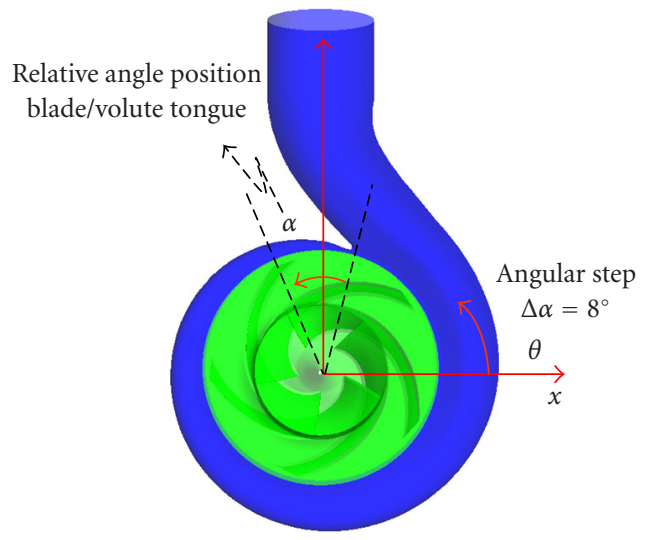

FIGURE 12: Relative positions between blade trailing edge and volute tongue.

TABLE 4: Matrix of proposed quasi-unsteady flow simulations.

\begin{tabular}{|c|c|c|c|c|c|c|c|c|c|}
\hline \multirow{2}{*}{ flow rate ratio } & \multicolumn{7}{|c|}{$\alpha$} \\
\hline & $0^{\circ}$ & $8^{\circ}$ & $16^{\circ}$ & $24^{\circ}$ & $32^{\circ}$ & $40^{\circ}$ & $48^{\circ}$ & $56^{\circ}$ & $64^{\circ}$ \\
\hline 0.5 & & & & & & & & & \\
\hline 0.7 & & & & & & & & & \\
\hline 0.8 & & & & & & & & & \\
\hline 0.9 & & & & & & & & & \\
\hline 1.0 & & & & & & & & & \\
\hline 1.2 & & & & & & & & & \\
\hline 1.4 & & & & & & & & & \\
\hline
\end{tabular}

zero. The remaining relative positions correspond to an impeller rotation $\Delta \alpha=8^{\circ}$ (see Figure 12). The matrix of the performed simulations is shown in Table 4 .

The general simulation parameters for the impellervolute assembly are summarized in Table 5 .

The CFD simulation offers a virtual image of the internal flow in the machine allowing the analysis and comprehension of more complex phenomena. The flow is strongly influenced by the asymmetry introduced by the volute casing and the volute tongue position. First, the flow field at the mean plane, normal to the rotating axis (rotational plane), is presented for the BEP flow rate of the pump. The velocity vectors in the impeller (relative vector) and volute casing (absolute vector) are shown in Figure 13 for $\alpha=0^{\circ}$. Although there is a good guidance of the flow in the volute, a strong recirculation zone appears at the volute diverging outlet. Inside the impeller, the flow velocities are relatively uniform for all blade passages. This behavior was observed for all analyzed relative positions.

Figure 14 shows the static pressure field at the mean rotational plane. Even though the effect of the volute tongue is appreciable, a relatively uniform pressure distribution is obtained around the impeller. This tendency was also obtained for different positions of the impeller (see Figures 15 and 16).
TABLE 5: Impeller-volute assembly simulation parameters.

\begin{tabular}{lc}
\hline Parameter & CFX-5 \\
\hline Domain of simulation & $\begin{array}{c}\text { Whole impeller }(5 \text { blade } \\
\text { passages })+ \text { volute }\end{array}$ \\
Extended inlet duct grid & $\begin{array}{c}\text { Unstructured } 104973 \text { nodes } \\
\text { Structured } 355225 \text { nodes }\end{array}$ \\
Impeller grid & Unstructured 217753 nodes \\
Volute casing grid & Total pressure $=101325 \mathrm{~Pa}$ \\
Inlet & Frozen rotor \\
Interface duct / impeller & Frozen rotor \\
Interface impeller / volute & Mass flow \\
Outlet & $\kappa-\varepsilon$ \\
Turbulence model & Second order \\
Discretization &
\end{tabular}

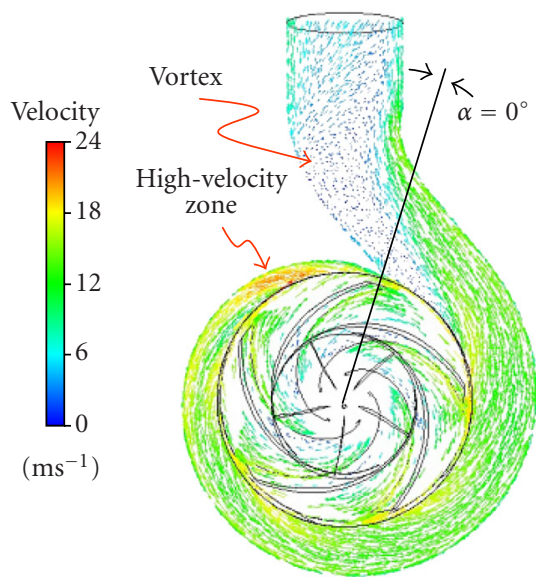

FIGURE 13: Velocity vectors of pump NS32 at the best efficiency point $\left(Q / Q_{\text {bep }}=1\right)$ and $\alpha=0^{\circ}$.

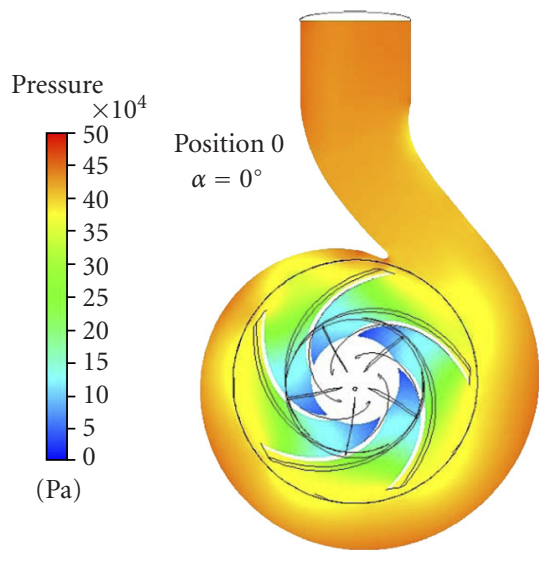

FIGURE 14: Static pressure field of pump NS32 at the best efficiency point $\left(Q / Q_{\text {bep }}=1\right)$ and $\alpha=0^{\circ}$.

The impeller-volute interaction is evidenced by a nonuniform pressure distribution at the impeller periphery. The static pressure distribution for the pump BEP flow rate and 


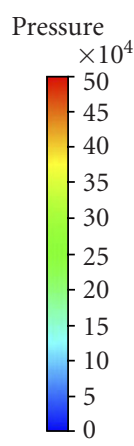

$(\mathrm{Pa})$

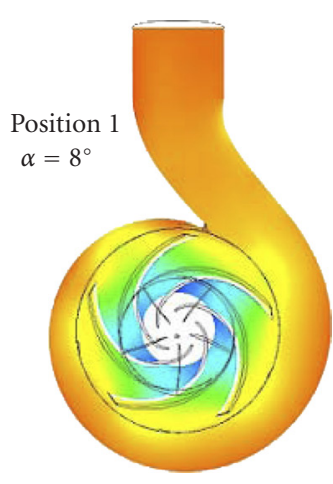

(a)

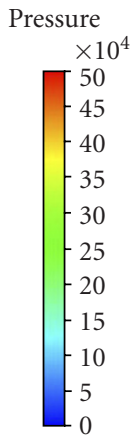

$(\mathrm{Pa})$

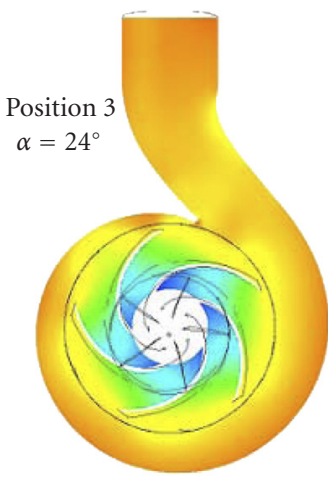

(c)

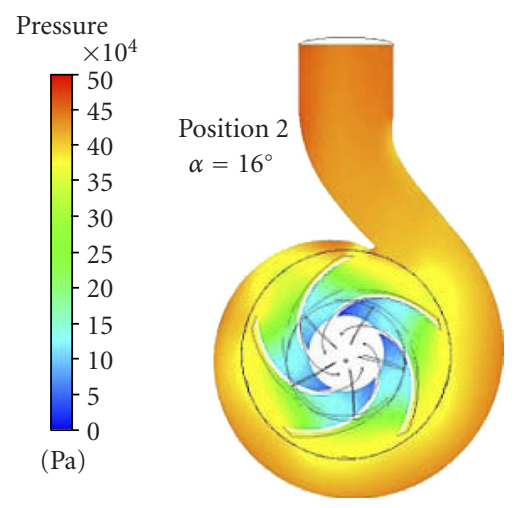

(b)

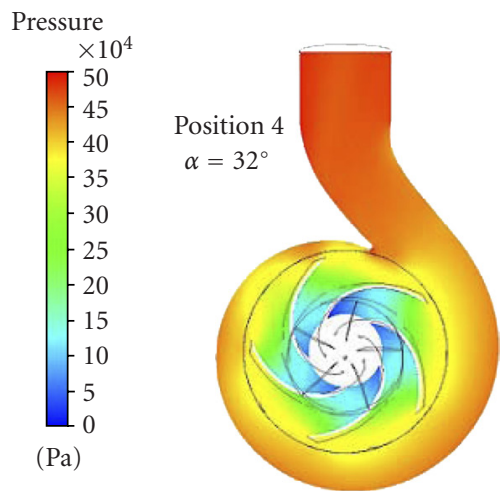

(d)

FIGURE 15: Static pressure field of pump NS32 at the best efficiency point $\left(Q / Q_{\text {bep }}=1\right)$ for different relative positions of impeller-volute tongue.

$\alpha=0^{\circ}$ is presented in Figure 17. The pressure pulsation amplitudes reach $27 \%$ of the mean pressure generated by the impeller.

Figures 18 and 19 show the influence of the pump flow rate on flow kinematics. In Figures 18 and 19, the velocity and pressure fields for different pump capacities $\left(0.5 Q_{b e p}\right.$, $0.8 Q_{\text {bep }}, 1.0 Q_{\text {bep }}$, and $\left.1.2 Q_{\text {bep }}\right)$ and $\alpha=0^{\circ}$ are shown.

For the BEP flow rate, the fluid is well conducted by the volute leading to a uniform operation of the impeller. There are not large differences in the velocity and pressure fields for the various blade passages. On the other hand, a more significant variation in velocity and pressure is observed when the pump operates off the best efficiency point.

For flow rates larger than that at BEP, the blade passage arriving at the volute tongue undergoes a strong pressure drop (see Figure 20). Therefore, this area favors the appearance of cavitation. This phenomenon has been reported in the literature by Bakir et al. [16] and Kouidri et al. [17].

The opposite occurs for partial pump capacities. The blade passage leaving the volute tongue experiences the largest pressure gradient. This effect is hardly noticeable when the pump flow rate is reduced to $0.8 Q_{\text {bep }}$, but accentuated when the flow rate is reduced to $0.5 Q_{\text {bep }}$.

\subsection{Radial trust}

The nonuniform pressure distribution around the impeller periphery is the origin of periodic loads causing the radial trust. This fundamental parameter affects the life cycle of the pump shaft and bearings as well as the vibration behavior of the machine. The pressure distribution around the impeller periphery is shown in Figure 21 for $\alpha=0^{\circ}$ and different flow rates.

As expected, the weakest amplitudes pressure pulsation is found in the range BEP. For flow rates outside this range, (0.5 $Q_{\text {bep }}$ and $\left.1.4 Q_{\text {bep }}\right)$ pressure pulsations are more significant and can reach up $50 \%$ of relative values.

The radial trust can be determined from the pressure distributions by carrying out the integration of the elementary forces around the impeller periphery (see Figure 22).

As a function of the angle $\theta$, the elementary force is written as

$$
d \vec{F}(\theta)=p(\theta) \cdot d S \cdot \hat{n}
$$




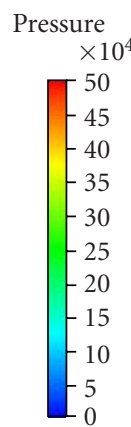

(Pa)

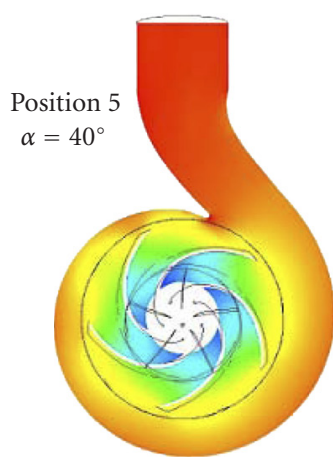

(a)

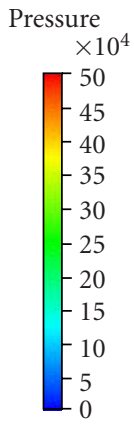

(Pa)

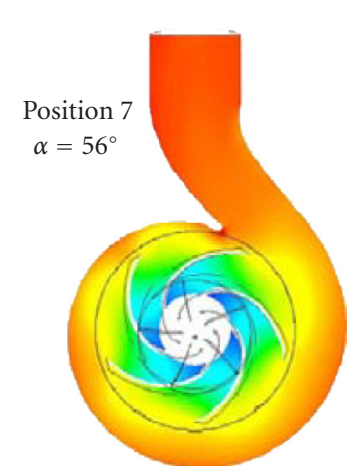

(c)

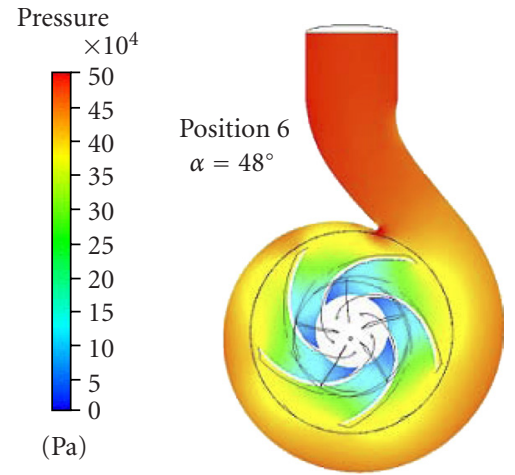

(b)

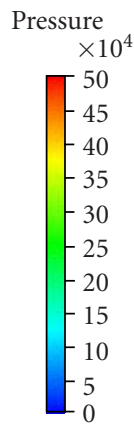

(Pa)

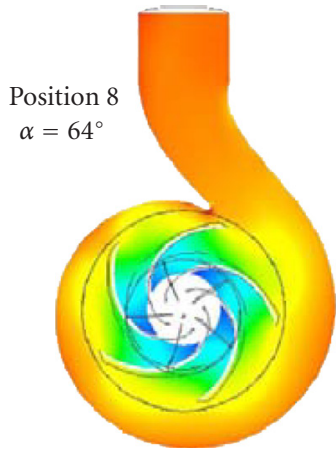

(d)

FIGURE 16: Static pressure field of pump NS32 at the best efficiency point $\left(Q / Q_{\text {bep }}=1\right)$ for different relative positions of impeller-volute tongue.

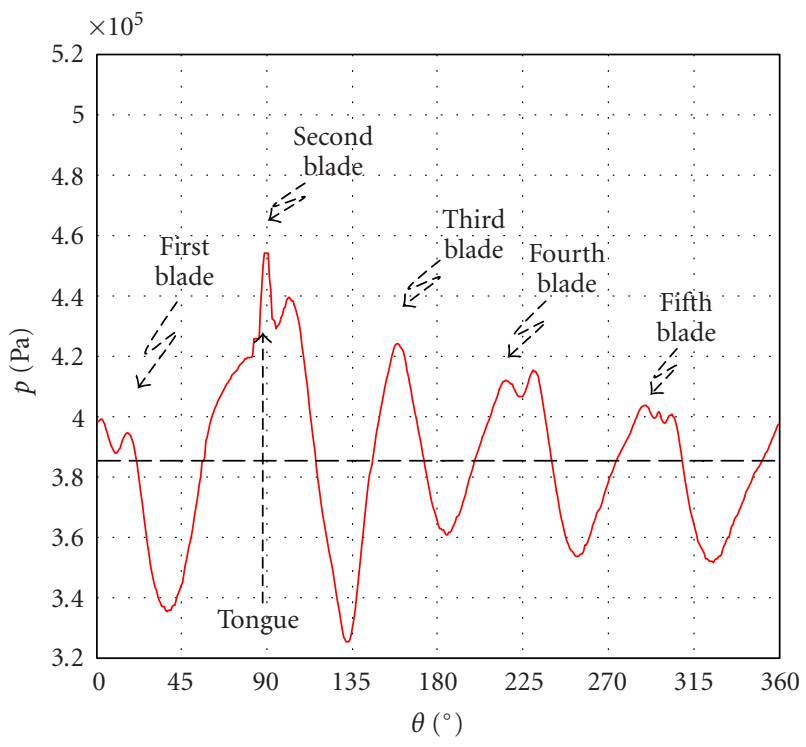

FIGURE 17: Static pressure distribution at the impeller periphery, for $Q / Q_{\text {bep }}=1$ and $a=0^{\circ}$.
The two Cartesian components of this force are

$$
\begin{aligned}
& d F_{x}(\theta)=p(\theta) \cdot d S \cdot \cos \theta \\
& d F_{y}(\theta)=p(\theta) \cdot d S \cdot \sin \theta
\end{aligned}
$$

The components of the resulting force $F_{x}$ and $F_{y}$ are determined by the integrals

$$
\begin{aligned}
& F_{x}=\int_{0}^{2 \pi} d F_{x}(\theta) d \theta, \\
& F_{y}=\int_{0}^{2 \pi} d F_{y}(\theta) d \theta .
\end{aligned}
$$

Finally, the resulting radial force is written

$$
F=\sqrt{F_{x}^{2}+F_{y}^{2}} .
$$

The radial trust $F$ has been calculated for different relative 


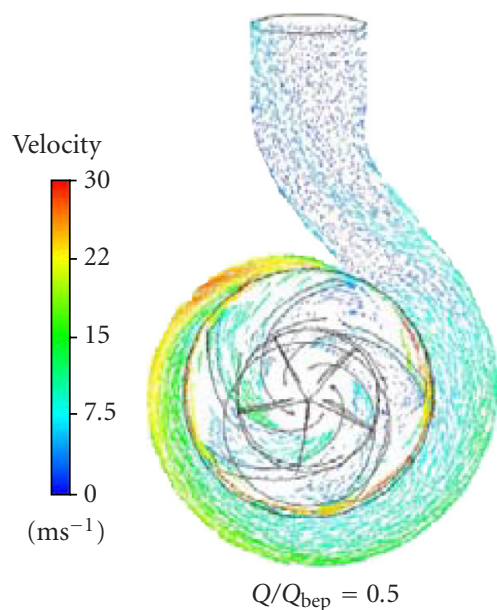

(a)

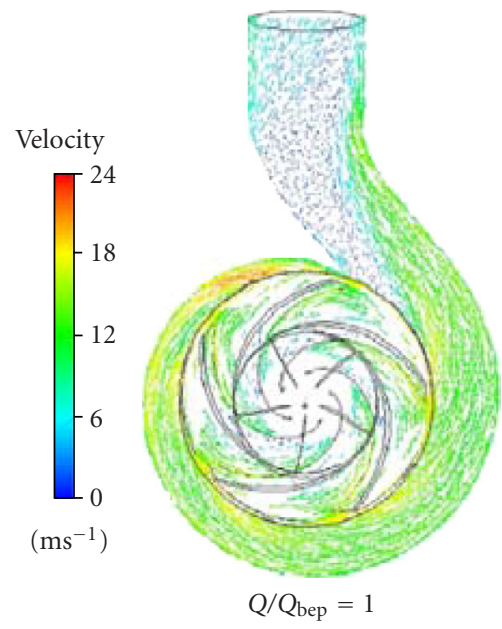

(c)

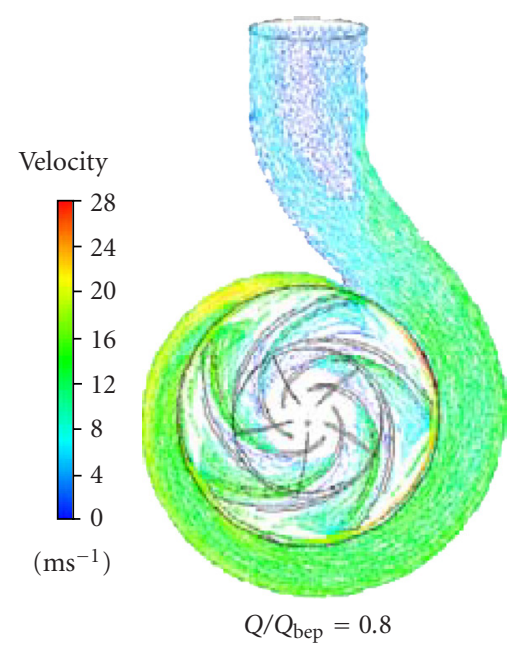

(b)

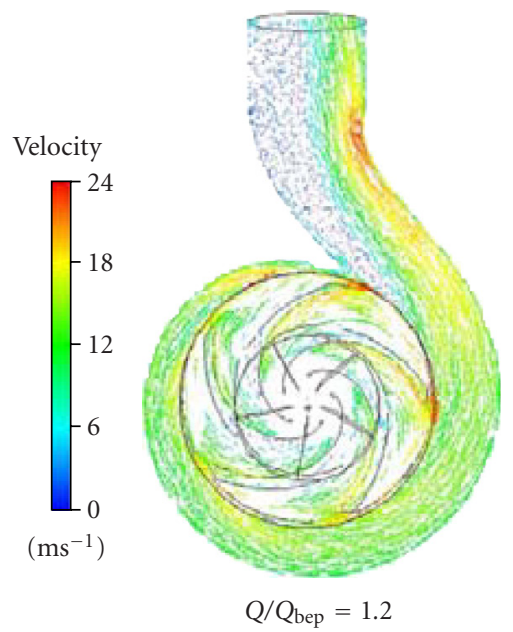

(d)

Figure 18: Velocity field at different pump capacities.

positions, the results are presented in Figure 23. The direction and module of the radial force change according to the relative position between the impeller and volute tongue.

Figure 24 shows the amplitudes of the radial force as function of the pump flow rate for $\alpha=0^{\circ}$. As it can be observed, this curve reaches a minimum at the BEP pump flow rate and the radial force values are comparable to those obtained by an empirical correlation suggested by Stepanoff [18].

\section{CONCLUSIONS}

In this research work, an integral procedure for the optimization of centrifugal pumps has been developed based on 3D quasi-unsteady flow simulation using CFX-TASCflow and CFX 5.5 codes.

The sensitivity study performed on the isolated impeller has shown two relevant aspects.

(i) The numerical solution is stabilized with grids containing more than 40000 nodes.

(ii) All turbulence models used $(k-\varepsilon, k \omega, k-\omega, S S T)$ gave almost identical results, for the same simulating conditions.

The impeller-volute assembly requires the addition of two extended computational domains; one at the impeller inlet and the other at the volute outlet. The Frozen-Rotor interface model (quasi-unsteady) is considered for the study of the impeller-volute assembly since it represents the best accuracy of computing time tradeoff. 


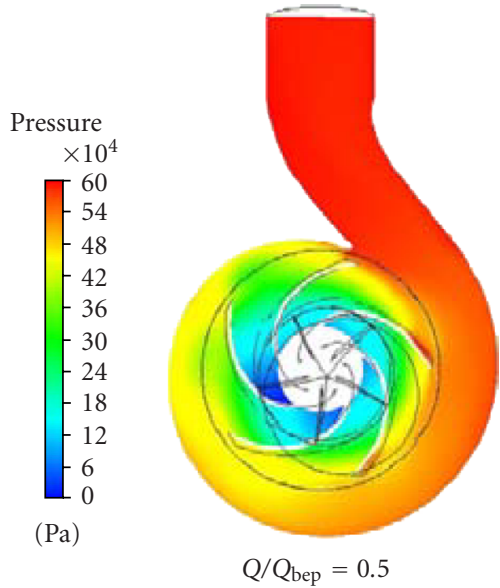

(a)

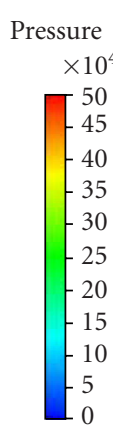

$(\mathrm{Pa})$

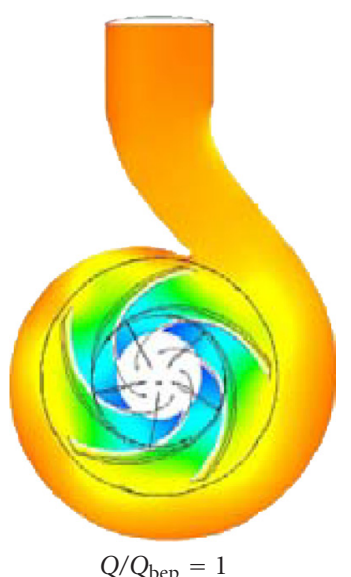

(c)

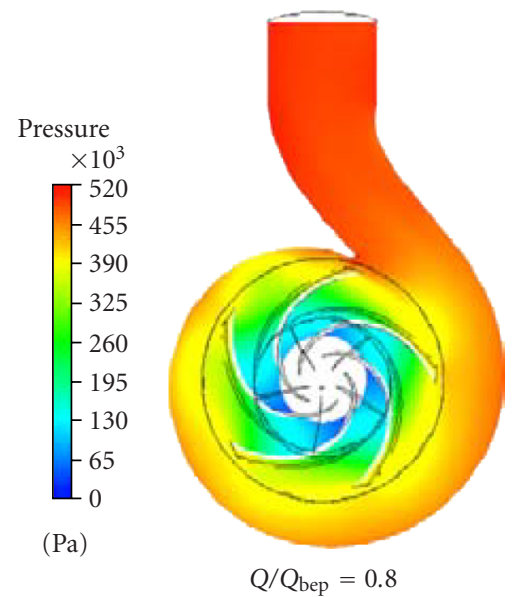

(b)

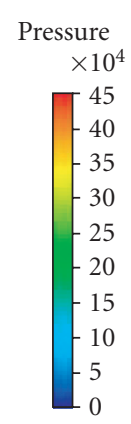

$(\mathrm{Pa})$

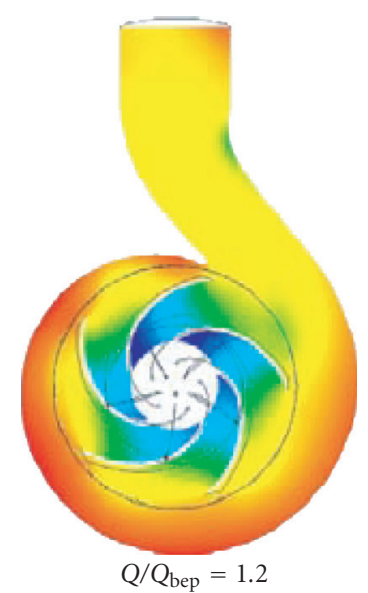

(d)

Figure 19: Pressure field at different pump capacities.

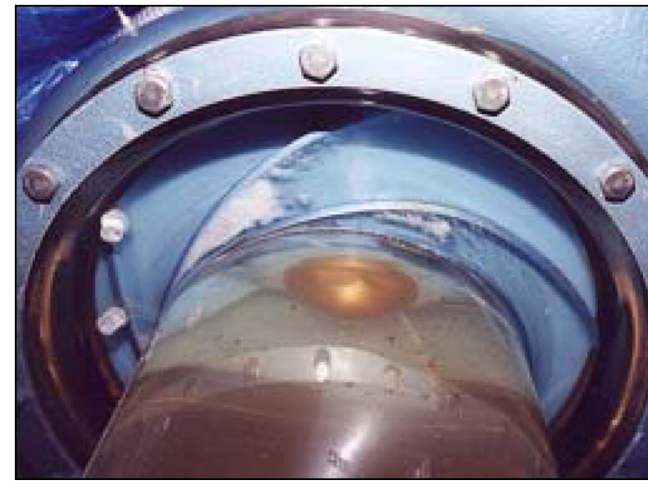

FIgURE 20: Experimental cavitation observation in two channels of impeller NS32 at capacity greater than that at the best efficiency point.

The main results of this study are the following.

(i) The volute tongue causes an unsymmetrical flow distribution in the impeller. As a consequence, a nonaxisymmetric cavitation appears in some of the blade

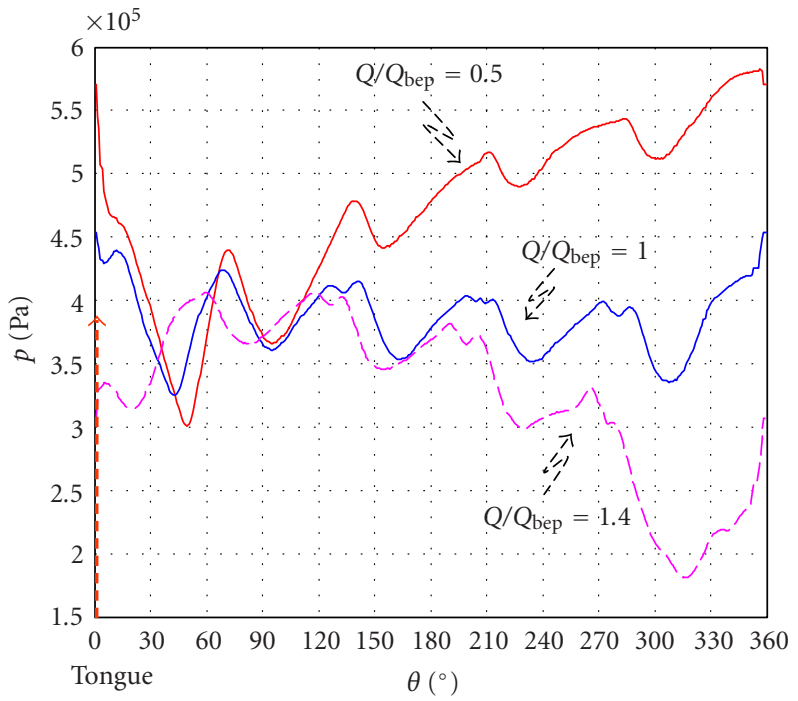

FIGURE 21: Static pressure distribution at the impeller periphery, for different pump capacities $\left(\alpha=0^{\circ}\right)$. 


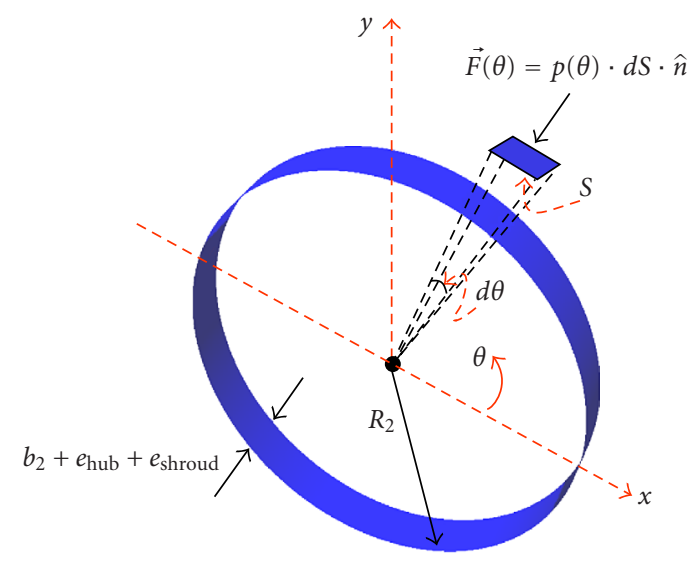

FIGURE 22: Radial force integration around impeller periphery.

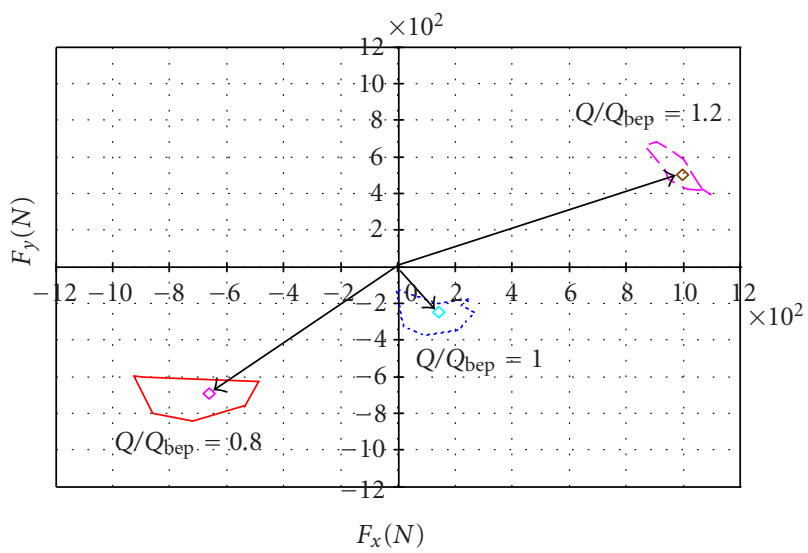

Figure 23: Module and direction of radial force at different pump capacities $\left(0.8 Q_{\text {bep }}, 1.0 Q_{\text {bep }}\right.$, and $\left.1.2 Q_{\text {bep }}\right)$.

passages of the impeller. These results are corroborated by experiments conducted on a centrifugal pump tested in the LEMFI test loop.

(ii) A nonuniform pressure distribution develops at the impeller periphery as a function of the pump flow rate, causing a fluctuating radial thrust of significant amplitude.

\section{ACKNOWLEDGMENTS}

The authors wish to thank all the collaboration provided by the following institutions, without whom the developing of this work would not have been possible: Programme de Coopération de Postgraduée France-Venezuela, Fondo Nacional de Ciencia, Tecnología e Innovación FONACIT, and the Embassy of France in Venezuela.

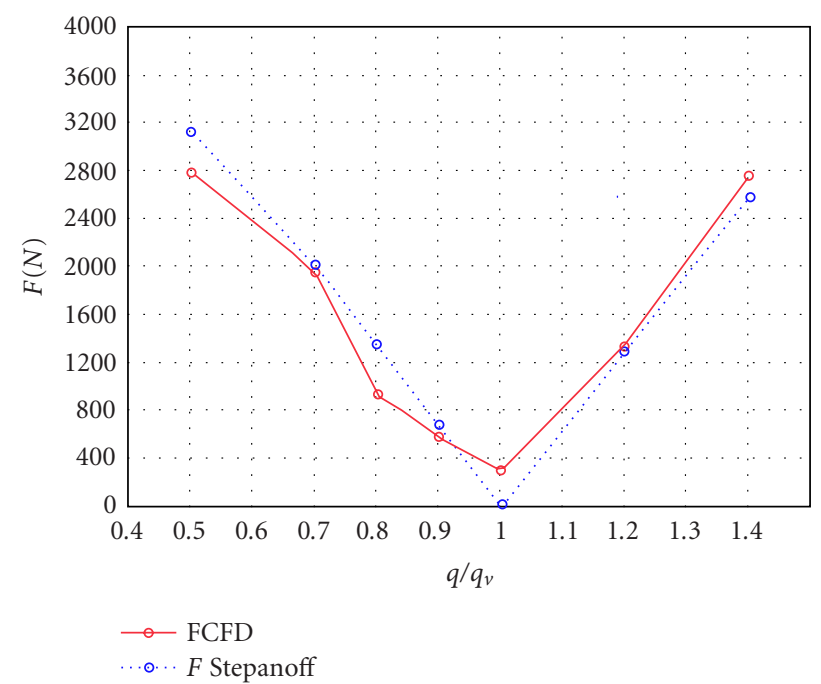

FIGURE 24: Radial thrust versus flow rate ratio, NS32 pump, $\alpha=0^{\circ}$.

\section{REFERENCES}

[1] H. Paßrucker and R. A. Van den Braembussche, "Inverse design of centrifugal impellers by simultaneous modification of blade shape and meridional contour," in Proc. 45th ASME International Gas Turbine and Aeroengine Congress and Exposition, Munich, Germany, May 2000.

[2] C. Cravero, "A design methodology for radial turbomachinery. Application to turbines and compressors," in Proc. ASME Fluids Engineering Division Summer Meeting (FEDSM '02), Montreal, Quebec, Canada, July 2002, paper FEDSM200231335.

[3] D. Sloteman, A. Saad, and P. Cooper, "Design of custom pump hydraulics using traditional methods," in Proc. ASME Fluids Engineering Division Summer Meeting (FEDSM '01), New Orleans, La, USA, May-June 2001, paper FEDSM2001-18067.

[4] A. Goto, M. Nohmi, T. Sakurai, and Y. Sogawa, "Hydrodynamic design System for pumps based on 3-D CAD, CFD, and inverse design method," Transactions of the ASME, Journal of Fluids Engineering, vol. 124, no. 2, pp. 329-335, 2002.

[5] A. Arnone, P. Boncinelli, A. Munari, and E. Spano, "Application of CFD techniques to the design of the Ariane 5 turbopump," in Proc. 14th AIAA Computational Fluid Dynamics Conference, Norfolk, Va, USA, June-July 1999, paper AIAA99-3380, p.10871097.

[6] M. Asuaje, F. Bakir, S. Kouidri, R. Noguera, and R. Rey, "Validation d'une démarche de dimensionnement optimisé des roues centrifuges $2 \mathrm{D}$ par comparaison avec les outils de la simulation numérique (CFD)," in 10ème Conférence Annuelle de la Société Canadienne de la CFD, pp. 560-565, Windsor, Ontario, Canada, June 2002.

[7] S. Yedidiah, "Science in the design of fluid machines," in Proc. ASME Fluids Engineering Division Summer Meeting (FEDSM '02), Montreal, Quebec, Canada, July 2002, paper FEDSM2002-31323.

[8] E. Blanco-Marigorta, J. Fernández-Francos, J. L. ParrondoGayo, and C. Santolaria-Morros, "Numerical simulation of centrifugal pumps," in Proc. ASME Fluids Engineering Summer Conference (FEDSM '00), Boston, Mass, USA, June 2000, paper FEDSM00-11162.

[9] J. González, J. Fernández-Francos, E. Blanco, and C. Santolaria-Morros, "Numerical simulation of the dynamic effects due to impeller-volute interaction in a centrifugal 
pump," Transactions of the ASME, Journal of Fluids Engineering, vol. 124, no. 2, pp. 348-355, 2002.

[10] J. L. Parrondo-Gayo, J. González-Pérez, and J. FernándezFrancos, "The effect of the operating point on the pressure fluctuations at the blade passage frequency in the volute of a centrifugal pump," Transactions of the ASME, Journal of Fluids Engineering, vol. 124, no. 3, pp. 784-790, 2002.

[11] F. Gu, A. Engeda, M. Cave, and J.-L. Di Liberti, "A numerical investigation on the volute/diffuser interaction due to the axial distortion at the impeller exit," Transactions of the ASME, Journal of Fluids Engineering, vol. 123, no. 3, pp. 475-483, 2001.

[12] F. Muggli, P. Holbein, and P. Dupont, "CFD calculation of a mixed flow pump characteristic from shut-off to maximum flow," in Proc. ASME Fluids Engineering Division Summer Meeting (FEDSM '01), New Orleans, La, USA, May-June 2001, paper FEDSM2001-18072.

[13] C. Cravero and M. Marini, "Modeling of incompressible three-dimensional flow in rotating turbomachinery passages," in Proc. ASME Fluids Engineering Division Summer Meeting (FEDSM '02), Montreal, Quebec, Canada, July 2002, paper FEDSM2002-31177.

[14] J. H. Ferziger and M. Péric, Computational Methods for Fluid Dynamics, Springer, Berlin, Germany, 1996.

[15] P. Bradshaw, "Turbulence modeling with application to turbomachinery," Progress in Aerospace Sciences, vol. 32, no. 6, pp. 575-624, 1996.

[16] F. Bakir, S. Kouidri, T. Belamri, and R. Rey, "On a general method of unsteady potential calculation applied to the compression stages of a turbomachine-Part I: Theoretical approach," Transactions of the ASME, Journal of Fluids Engineering, vol. 123, no. 4, pp. 780-786, 2001.

[17] S. Kouidri, T. Belamri, F. Bakir, and R. Rey, "On a general method of unsteady potential calculation applied to the compression stages of a turbomachine-Part II: Experimental comparison," Transactions of the ASME, Journal of Fluids Engineering, vol. 123, no. 4, pp. 787-792, 2001.

[18] A. J. Stepanoff, Centrifugal and Axial Flow Pumps, John Wiley \& Sons, New York, 1957. 

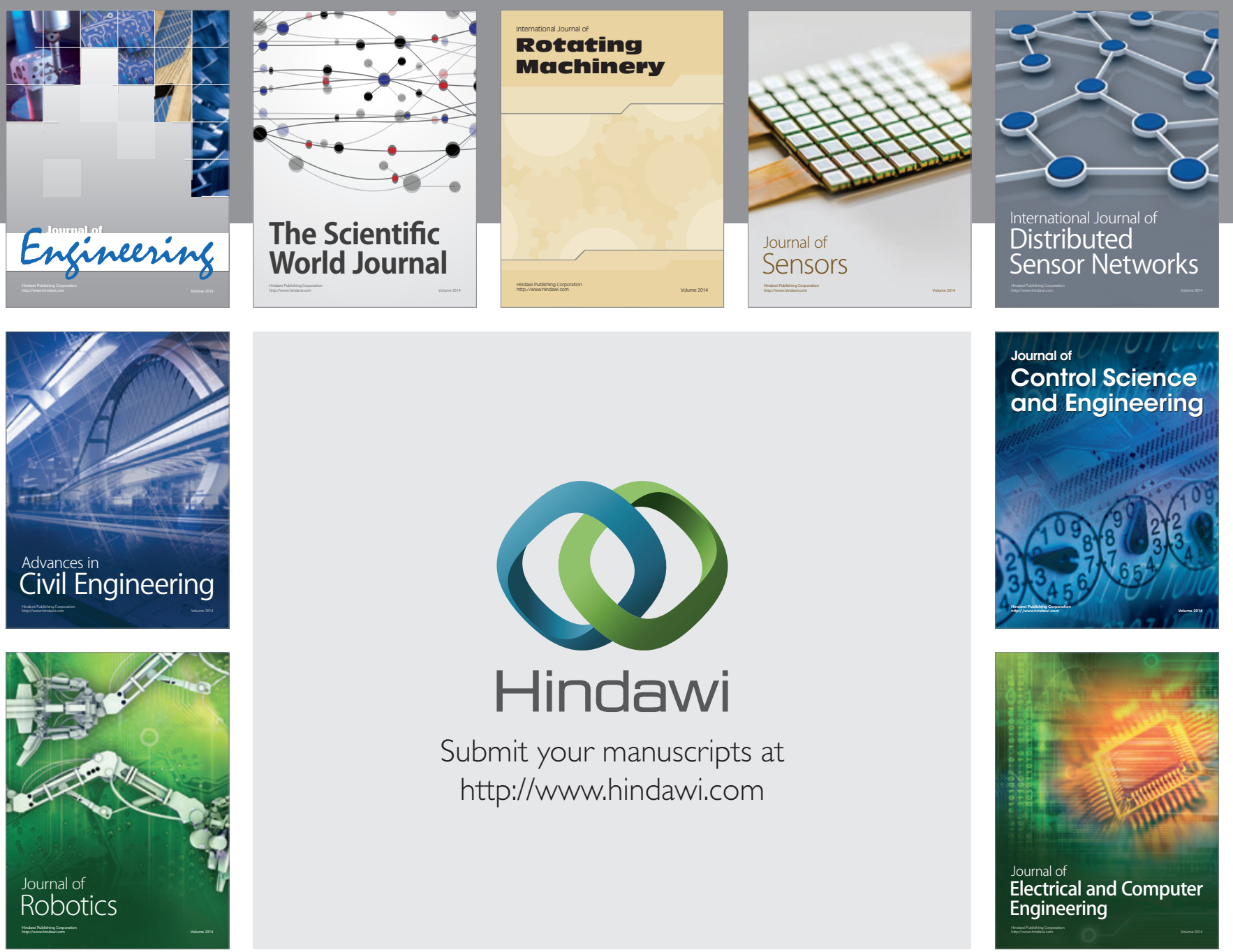

Submit your manuscripts at

http://www.hindawi.com
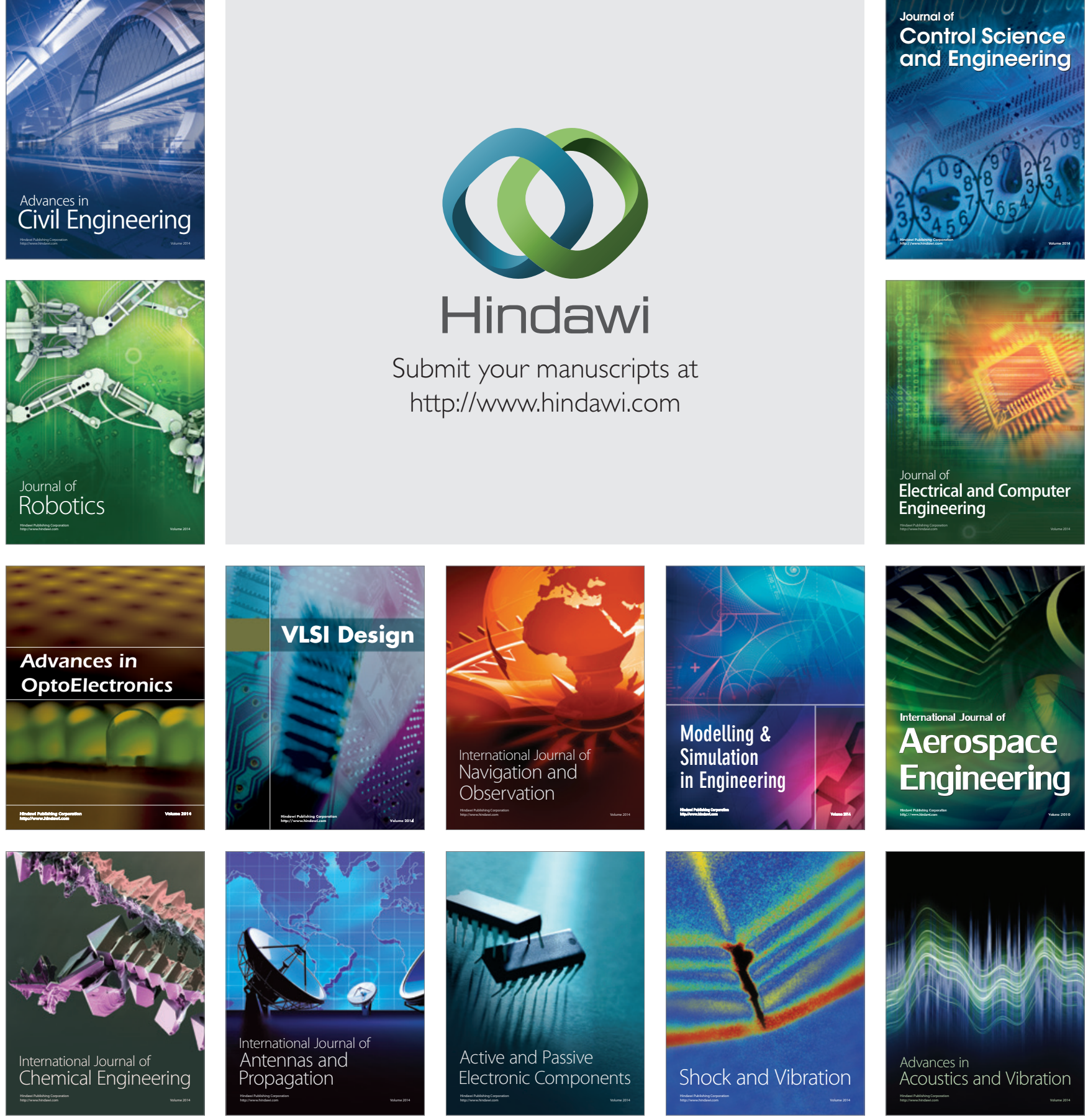